\title{
Clinical Significance of a Duplicated Palmaris Longus Muscle with One Reversed Muscle: A Case Report
}

\author{
Adegbenro Omotuyi John Fakoya ${ }^{1 *}$, Jordan D'Souza ${ }^{2}$, Andrea Mary Thomas Kallumadyil ${ }^{2}$, Tess McClenahan ${ }^{2}$, Allyson Talaroc $^{2}$, \\ Ananya Vungarala ${ }^{2}$, Abayomi Gbolahan Afolabi ${ }^{1}$, Thomas McCracken ${ }^{1}$, David Otohinoyi ${ }^{3}$ \\ ${ }^{1}$ Department of Anatomy, University of Medicine and Health Sciences, Basseterre, St. Kitts and Nevis; ${ }^{2}$ Medical student, \\ University of Medicine and Health Sciences, Basseterre, St. Kitts and Nevis; ${ }^{3}$ Department of Research, All Saints University \\ College of Medicine, Arnos Vale, St. Vincent \& Grenadines
}

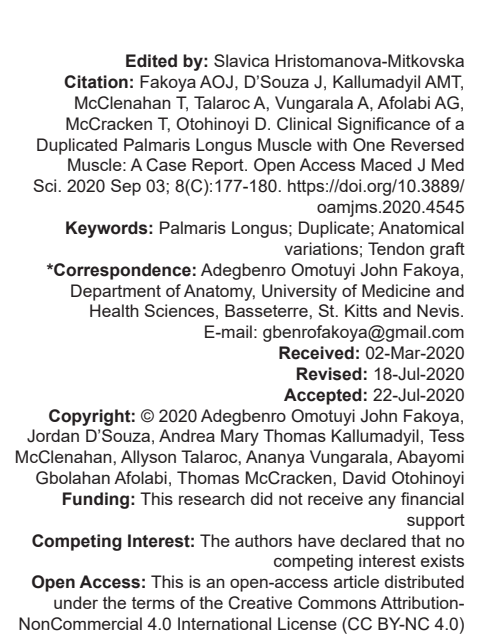

Introduction

The palmaris longus $(P L)$ is a superficial muscle of the anterior compartment of the forearm. Its muscle body originates at the medial epicondyle of the humerus and projects over the transverse carpal ligament to insert its tendon into the palmar aponeurosis [1]. The PL is located superficially to the flexor digitorum, medial to the flexor carpi radialis, and lateral to the flexor carpi ulnaris [2].

Through comparative anatomy, the common function of the PL among human and non-human primates is to flex the wrist. The strength of the muscle decreases as you progressively compare the ancestral genera of primates to more derived primate species, supporting claims of phylogenetic regression of the $\mathrm{PL}$ through evolution [2], [3]. Subsequently, in the evolutionarily derived human primate, the PL muscle is less developed and is one of the most morphologically variable muscles of the upper limb [4], [5].

Reimann et al. documented most variations of the PL [6]. The most common variation of the PL is bilateral or unilateral agenesis. Around the world, the prevalence rate of absence ranges from $1.5 \%$ to $63.9 \%$ [7]. Although, the absence of PL is not easily noticed by individuals due to the compensatory flexors in the anterior compartment of the forearm [8]. Other frequently observed variations of the PL include bifurcation of the distal tendon, bifurcation of the proximal insertion, insertion into adductor pollicis brevis, and multiple reversed heads [4], [9]. These observations provide insight into the vast potential of variations possible of the PL as its function continues to regress through primate evolution.

Variations in the distal aspect of the PLare clinically significant due to its proximity to both the median and ulnar nerve. Compression of the median and ulnar nerve by the PL can lead to symptoms of carpal tunnel syndrome and Dupuytren's contracture, respectively [5], [10]. Furthermore, awareness of different variations is essential to prevent misidentification and accidental damage to the muscles of the forearm during surgical exploration [5].

The purpose of this case report is to explore a rare unilateral PL variation: The duplication of the PL, where one is normal, and one is reversed. To the best 
of our knowledge, this exact variation has only been documented once in the literature [3]. This case report will furthermore attempt to describe the PL variation and hypothesize possible clinical significance by examining the current literature.

\section{Case Report}

The PL variation was found during the dissection of a 70-year-old Caucasian male cadaver, at the University of Medicine and Health Sciences, St. Kitts. During dissection, the left upper limb was deskinned from the shoulder down to the distal portion of the antebrachium. Removing the superficial fascia revealed the double PL variation in the anterior compartment. Furthermore, one of the two muscle heads was reversed (Figure 1).

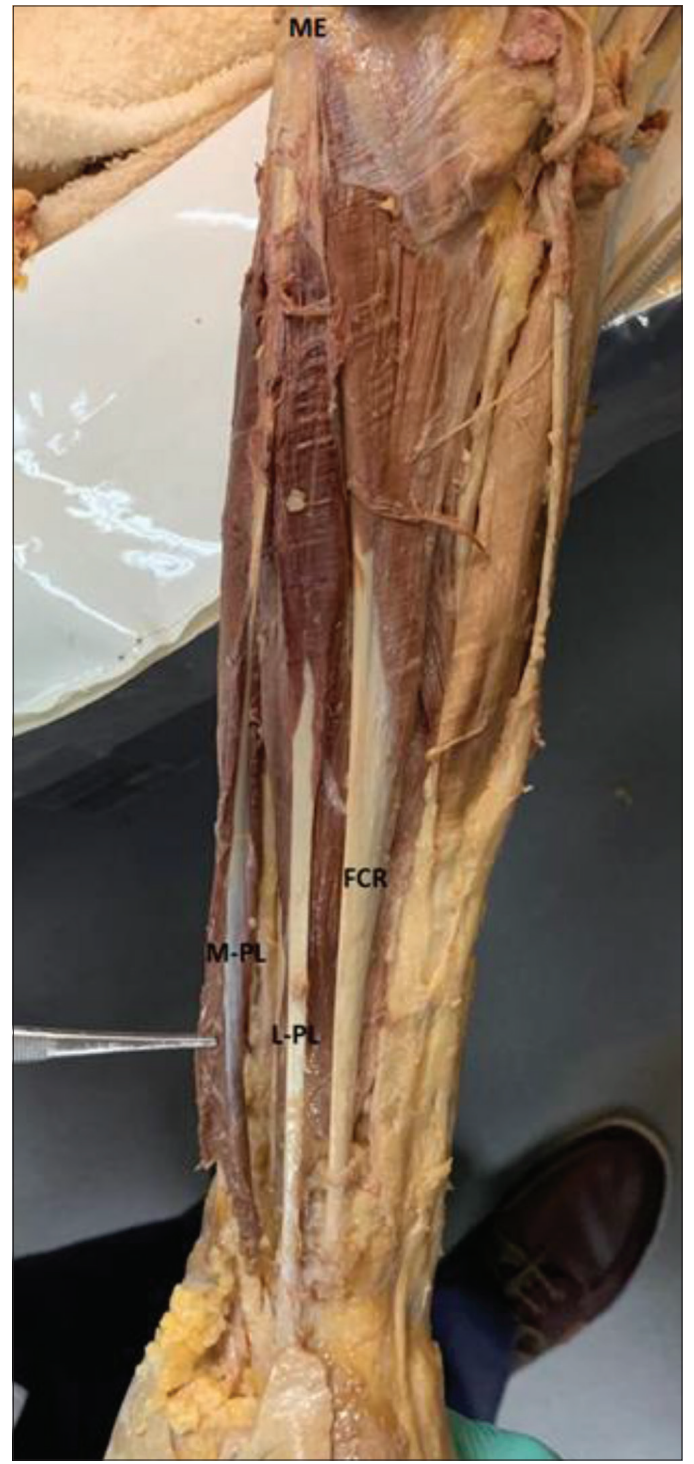

Figure 1: Unilaterally duplicated palmaris longus variation with one reversed muscle. FCR: Flexor carpi radialis, L-PL: Lateral palmaris longus, M-PL: Medial palmaris longus, ME: Medial epicondyle
The lateral muscle head resembled a normal $\mathrm{PL}$ muscle; a short proximal tendon originating on the medial epicondyle, a short muscle belly, and a long distal tendon inserting onto the palmar aponeurosis [11] (Figure 1). In contrast, the reversed (medial) PL had a long proximal head originating on the medial epicondyle, a short muscle belly, and a short distal tendon inserting into the palmar aponeurosis (Figure 2).

Despite having a PL variation, the vasculature and innervation of the muscles were normal, consisting of branches of the ulnar artery and the median nerve, respectively [12].

\section{Discussion}

Agenesis occurs in about $10 \%$ of the world's population, despite the variation observed among different races and genders [6]. As noted in Table 1, the variation discussed in this case report has only been documented once.

The cadaver's left forearm presented with a duplicate PL muscle with its medial head in reversed

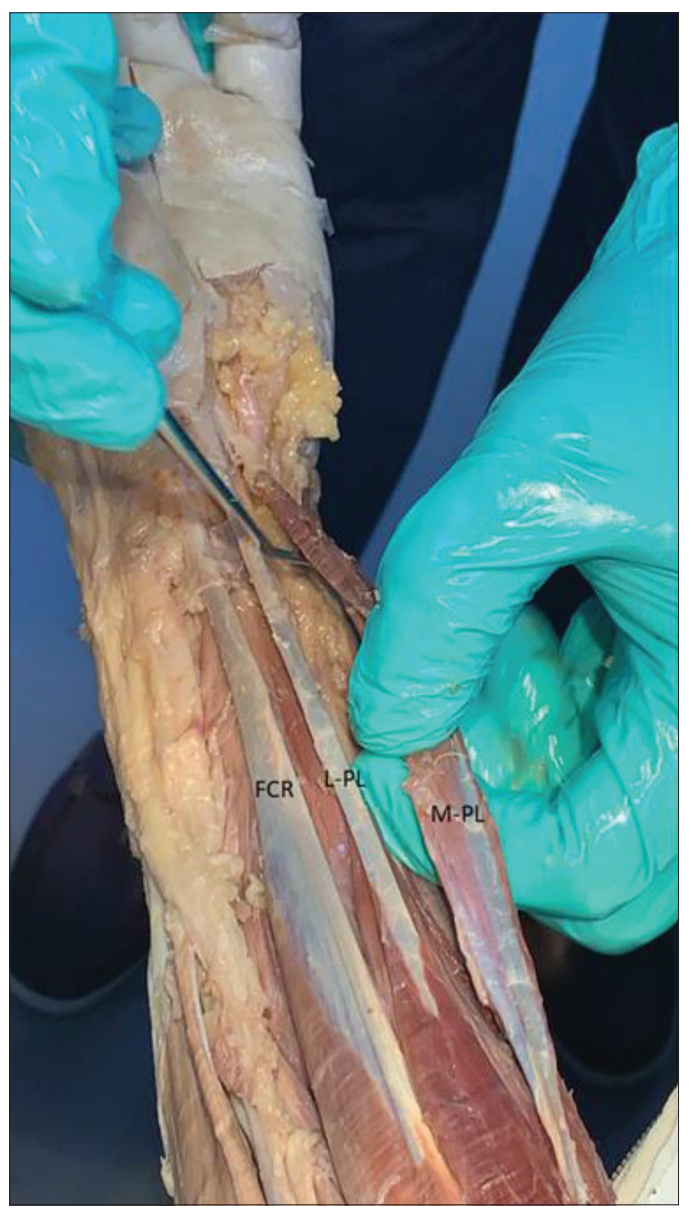

Figure 2: Distal tendons of the reversed palmaris longus muscles, the lateral muscle having a completely tendinous insertion and the other a musculotendinous insertion. FCR: Flexor carpi radialis, L-PL: Lateral palmaris longus, M-PL: Medial palmaris longus 
Table 1: Documented variations of the palmaris longus muscle

\begin{tabular}{|c|c|}
\hline Palmaris longus variations & References \\
\hline \multirow[t]{9}{*}{ Agenesis } & Reimann et al. (1944) \\
\hline & Troha et al. (1990) \\
\hline & Ceyhan and Mavt (1997) \\
\hline & Thompson (2001) \\
\hline & Sebastin et al. (2005) \\
\hline & Kapoor et al. (2008) \\
\hline & Pai et al. (2008) \\
\hline & Kigera and Mukwaya (2011) \\
\hline & Yammine (2013) \\
\hline \multirow[t]{4}{*}{ Duplication/triplication } & Macalister (1875) \\
\hline & Reimann et al. (1944) \\
\hline & Mori (1964) \\
\hline & Georgiev et al. (2009) \\
\hline \multirow[t]{9}{*}{ Reversed muscle-tendon orientation } & Macalister (1875) \\
\hline & Meyer and Pflaum (1978) \\
\hline & Giunta et al. (1993) \\
\hline & Ninkovic et al. (1995) \\
\hline & Depuydt et al. (1998) \\
\hline & Pai et al. (2008) \\
\hline & Georgiev et al. (2009) \\
\hline & Twoon et al. (2017) \\
\hline & Bhashyam et al. (2017) \\
\hline \multirow{5}{*}{$\begin{array}{l}\text { Duplication/triplication with reversed muscle-tendon } \\
\text { orientation }\end{array}$} & Schlafly and Lister (1987) \\
\hline & Yildiz et al. (2000) \\
\hline & Natsis et al. (2007) \\
\hline & Salgado et al. (2012) \\
\hline & Longhurst et al. (2019) \\
\hline \multirow{2}{*}{$\begin{array}{l}\text { Duplicate PL with reversal of muscle-tendon orientation } \\
\text { in one muscle }\end{array}$} & Pai et al. (2008) \\
\hline & Our study \\
\hline Digastric muscle & Macalister (1875) \\
\hline Reversed PL with abductor digiti minimi & Georgiev and Jelev (2017) \\
\hline PL with the intermediate orientation of muscle & Kachlik et al. (2016) \\
\hline PL profundus & $\begin{array}{l}\text { Floyd et al. (1990) - bilateral } \\
\text { Dyreby et al. (1982) }\end{array}$ \\
\hline Multiple tendinous insertions of $\mathrm{PL}$ & Kumar et al. (2006) \\
\hline
\end{tabular}

PL: Palmaris longus

position. This variation was unilateral, as there were no observations of anomalies in the right PL. PL variations may result in carpal tunnel syndrome by compression of the median nerve due to the PL's close relationships to the transverse carpal ligament and median nerve [14]. Thus, the proximity of the reversed muscle head to the wrist may have elevated the risk of carpal tunnel syndrome in this cadaver from possible compression of the transverse carpal ligament, median nerve, and other contents of the carpal tunnel.

The variation of the PL may have compromised its function as a weak flexor of the wrist. However, because other muscles of the anterior forearm compartment can flex the wrist, it is unlikely that this action was altered. Neither head appeared atrophied on observation; therefore, it is likely the muscles performed their normal function, with neither muscle head favored over the other.

In case reports of pain during physical activity, such as swimming, due to the reversal of the PL, surgical resection relieved the pain entirely after failed attempts of non-operative therapies [15]. Considering our cadaver presented with one head reversed and one head in the normal position, it is unclear whether it would have caused pain during physical activity involving frequent flexion of the wrist.

While the PL muscle may have originally been involved with flexion of the metacarpophalangeal joints, its current mechanical role is that of a collateral wrist flexor [16]. The nominal wrist flexor role makes the PL a popular tendon graft source. The variation discussed in this case report presents an additional source for tendon grafts.

\section{Conclusion}

The case described above is the second case of its type. It is imperative for surgeons and other healthcare providers to be aware of possible complications regarding common variations of the $\mathrm{PL}$ as it is clinically important for tendon grafting in surgery, symptomatic clinical presentations, and an anatomical landmark.

\section{Acknowledgment}

The author would like special thank to the individual who donated their body to science and for our educational purposes.

\section{References}

1. Salgado G, Cantin O, Moños M, Saez J, Macuer M. Bilatera reversed palmaris longus muscle: A rare anatomical variation. Folio Morphol. 2012;71(1):52-5.

PMid:22532187

2. Aversi-Ferreira R, Bretas VR, Maior RS, Davaasuren M, Paraguassuú-Chaves, Nishijo $\mathrm{H}$ et al. Morphometric and statistical analysis of the palmaris longus muscle in human and non-human primates. BioMed Res Int. 2014;2014:6. https://doi. org/10.1155/2014/178906

3. Pai MM, Prabhu LV, Nayak SR, Madhyastha S, Vadgaonkar R, Krishnamurthy A, et al. The palmaris longus muscle: Its anatomic variations and functional morphology. Rom J Morphol Embryol. 2008;49(2):215-7.

PMid:18516329

4. Olewnik L, Waśneiewska $A$, Polguj $M$, Podgórski $M$, Labętowicz P, Ruzik K, et al. Morphological variability of the palmaris longus muscle in human fetuses. Surg Radiol Anat. 2018;40(11):1283-91. https://doi.org/10.1007/s00276-018-2069-2 PMid:30022223

5. Bashyam A, Harper C, lorio M. Reversed palmaris longus muscle causing volar forearm pain and ulnar nerve paresthesia. J Hand Surg Am. 2017;42(2):298. https://doi.org/10.1016/j. jhsa.2016.11.016

6. Reimann AF, Daseler EH, Anson BJ, Beaton LE. The palmaris longus muscle and tendon. A study of 1600 ex-tremities. Anat Rec. 1994;89(4):495-505. https://doi.org/10.1002/ ar.1090890408

7. Ioannisa D, Anastasiosb K, Konstantinosc N, Lazarosa K, Goergiosa N. Palmaris longus muscle's prevalence in different nations and interesting anatomical variations: Review of the literature. J Clin Med Res. 2015;7(11):825-30. https://doi. org/10.14740/jocmr2243w 


\section{PMid:26491493}

8. Thompson NW, Mockford BJ, Cran GW. Absence of the palmaris longus muscle: A population study. Ulster Med J. 2001;70(1):22-4.

PMid:11428320

9. Natsis K, Levva S, Totlis T, Anastasopoulous N, Paraskevas G. Three headed reversed palmaris longus muscle and its clinical significance. Ann Anat. 2007;189(1):97-101. https://doi. org/10.1016/j.aanat.2006.07.008 PMid:17319615

10. Keese GR, Wongworawat MD, Frykman G. The clinical significance of the palmaris longus tendon in the pathophysiology of carpal tunnel syndrome. J Hand Surg Br. 2006;31(6):657-60. https://doi.org/10.1016/j.jhsb.2006.07.015 PMid:16979803

11. Naveen K, Jyothsna P, Ravindra S, Surekha S, Abhinitha P, Mohandas R, et al. Presence of multiple tendinous insertions of palmaris longus: A unique variation of a retrogressive muscle. Ethiop J Health Sci. 2014;24(2):175-8. https://doi.org/10.4314/ ejhs.v24i2.11

PMid:24795520

12. Longhurst $G$, Stone $D$, Mahony N. Bilateral reversed palmaris longus muscle: A case report and systematic literature review.
Surg Radiol Anat. 2020;42(3):289-95. https://doi.org/10.1007/ s00276-019-02363-z

PMid:31720753

13. Christos L, Konstantinos N, Evagelos P. Revision of carpal tunnel release due to palmaris longus profundus. Case Rep Orthop. 2015;2015:616051. https://doi.org/10.1155/2015/616051 PMid:26075127

14. Getzmann J, Schweizer A. Surgical resection of a reversed palmaris longus muscle causing chronic exertional compartment syndrome in a competitive swimmer: A case report. Orthop J Sports Med. 2018;6(5):2325967118769615. https://doi. org/10.1177/2325967118769615 PMid:29881730

15. Twoon M, Jones CD, Foley J, Davidson D. Reversed palmaris longus muscle: A report of two cases. Case Reports Plast Surg Hand Surg. 2017;40(1):73-6. https://doi.org/10.1080/23320885. 2017.1353424

PMid:28804743

16. Georgiev GP, Iliev AA, Dimitrova IN, Kotov GN, Malinova LG Landzhov BV. Palmaris longus muscle variations: Clinical significance and proposal of new classifications. Folia Med. 2017;59(3):289-97. https://doi.org/10.1515/folmed-2017-0035 PMid:28976893 